\title{
WAVE OVERTOPPING AT DYKES WITH TOPPED VERTICAL WALL - IMPACTS OF OBLIQUE WAVE ATTACK
}

\author{
Nils B. Kerpen ${ }^{1}$ and Torsten Schlurmann
}

\begin{abstract}
Hydraulic model tests at a scale of 1:10 are carried out in a $40 \mathrm{~m} \times 25 \mathrm{~m}$ wave basin with a state-of-the-art 3D wave generator in order to collect wave overtopping data at vertical walls and dykes with topped vertical walls. Wave conditions in the near field of the structures, velocities under waves and the mean overtopping discharge are measured. The experiments have been commissioned by the Lower Saxony Water Management, Coastal Defense and Nature Conservation Agency (NLWKN) with the purpose to deliver essential overtopping data for validation of numerical models. Two main geometries are analyzed - each for two specific wave spectra. Overtopping rates are investigated with respect to the remaining freeboard height $R_{c}$ and the influence of oblique wave attack $\beta\left\{0^{\circ}, 10^{\circ}, 30^{\circ}, 40^{\circ}, 50^{\circ}, 60^{\circ}\right\}$. Results are compared with existing analytical approaches. As expected for this special geometrical coastal protection structure, it is examined that overtopping discharges increase with decreasing remaining freeboard. Intensity of the reduction is more dependent on the wave spectra than on the dyke geometry. Mean wave overtopping rate increases with decreasing relative water depth $H_{m} d d$ directly in front of the vertical wall. Furthermore, the mean wave overtopping rates decrease with an increasing angle of wave attack $\beta$. The correlation between mean wave overtopping rate and freeboard height is given in four newly adapted design formulas, describing the overtopping performance of the two discussed dyke geometries with topped vertical walls.
\end{abstract}

Keywords: wave overtopping; dyke; vertical wall; oblique wave attack.

\section{INTRODUCTION}

Sea level rise is identified to be most likely a consequence of climate change by Intergovernmental Panel on Climate Change (IPCC, 2007). Changing boundary conditions in coastal environments require an adaption of defense strategies along the coastlines. One possible measure is the construction of higher dykes to protect lives, infrastructure and tangible assets from the detrimental effects of storm surges. Many research studies focus on the overtopping problem at coast protection structures compiled on the European scale amongst others in the Assessment Manual for Wave Overtopping of Sea Defences and Related Structures by KFKI, hereafter named EurOtop (2007).

First studies dealing with wave run-up and wave overtopping affected by the impact of oblique wave attack at dykes were conducted by Wassing (1957). Wassing implemented a correction factor $\gamma_{f}$, considering oblique wave attack. In the following years, e.g. Tautenhain (1982), focused on wave runup and wave overtopping at dykes exposed to regular waves. Van der Meer and Janssen (1995) investigated wave run-up and overtopping phenomena at dykes in irregular and short crested waves. Franco (1999) and Napp et al. (2003) studied waves at vertical walls, while Goda (2009) improved the approach given in the EurOtop (2007) on the basis of data stemming from the CLASH project.

Urbanized areas along the estuaries at the German North Sea coast are typically protected by sea walls with an additional vertical submerged toe structure. Prediction of wave overtopping volumes is based on probabilistic approaches. The design of newly protection structures using state-of-the-art formulas from EurOtop (2007) includes a certain degree of uncertainty. Although former studies by Daemrich (2006) originated uncertainties in the interpretation of results from hydraulic overtopping model tests documented by a variety of design formulas for the determination of wave overtopping rates.

Due to this fact new physical model tests dealing with overtopping rates at dykes with topped vertical walls are investigated in a state-of-the-art 3D wave basin equipped with a multidirectional wave maker and active absorption technique. The aim of the present paper is to discuss the results of the hydraulic model tests with existing design formulas. The results will be used to validate the performance of a numerical model developed by the Coastal Research Center (FSK) of NLWKN.

\section{EXPERIMENTAL SETUPS, TEST CONDTIONS AND PROCEDURES}

The physical model tests (Froude scaling 1:10) dealing with wave overtopping performance at dykes with topped vertical walls are investigated in a state-of-the-art 3D wave basin equipped with a multidirectional wave maker and active absorption technique. The wave basin dimensions are $40 \mathrm{~m}$ in width and $25 \mathrm{~m}$ in length. A $28.8 \mathrm{~m}$ long multidirectional wave maker - consisting of 72 piston wave paddles - is used to generate nature-like wave spectra. An active absorption control assures implemented wave heights by effectively eliminating re-reflections at the wave machine in order to run experiments over longer time frames effectively.

\footnotetext{
${ }^{1}$ Franzius-Institute for Hydraulics, Waterways and Coastal Engineering, Leibniz Universität Hannover, Nienburger
} Str. 4, 30169 Hannover, Germany 
Two model dike geometries over a horizontal bed slope with topped vertical wall and an additional vertical submerged toe structure are tested (Figure 1-2). The second geometry has an additional 1:4 slope with a berm located directly in front of the topped vertical wall. Both structures are authentic design prototype walls designed for mean wave overtopping rates $q$ between $0.51 / \mathrm{sm}$ and $10 \mathrm{l} / \mathrm{sm}$. The dimensionless relative freeboard height $R$ defined by the crest freeboard $R_{c}$ normalized with the significant wave height $H_{m 0}$ varies between 0.85 and 1.8. Freeboard heights are altered by means of a variation of the still water level in the basin. The goal of the tests is to find the minimum freeboard while limiting the overtopping volume to $q=0.51 / \mathrm{sm}$. The physical model with an overall length of $13.35 \mathrm{~m}$ is located in the middle of the basin (Figure 3). As the wave maker is able to generate waves with up to $30^{\circ}$ according to its front the models are rotated by another $30^{\circ}$ in order to expand the bandwidth of experimental configurations for analyzing oblique wave attack. The model is separated into seven individual parts each of which is $1.9 \mathrm{~m}$ in width. Mean overtopping rates are measured in the five middle parts. Two additional wing walls compensate boundary effects and assure a homogeneous wave field in the five measuring areas. Data from mean wave overtopping rate are collected indirectly by measuring the water level in each of the five basins behind the sea wall with constant footprint over time. Furthermore, the wave field in front of the structure is recorded by 12 wave gauges and 2 velocity probes in three cross sections (Figure 4).

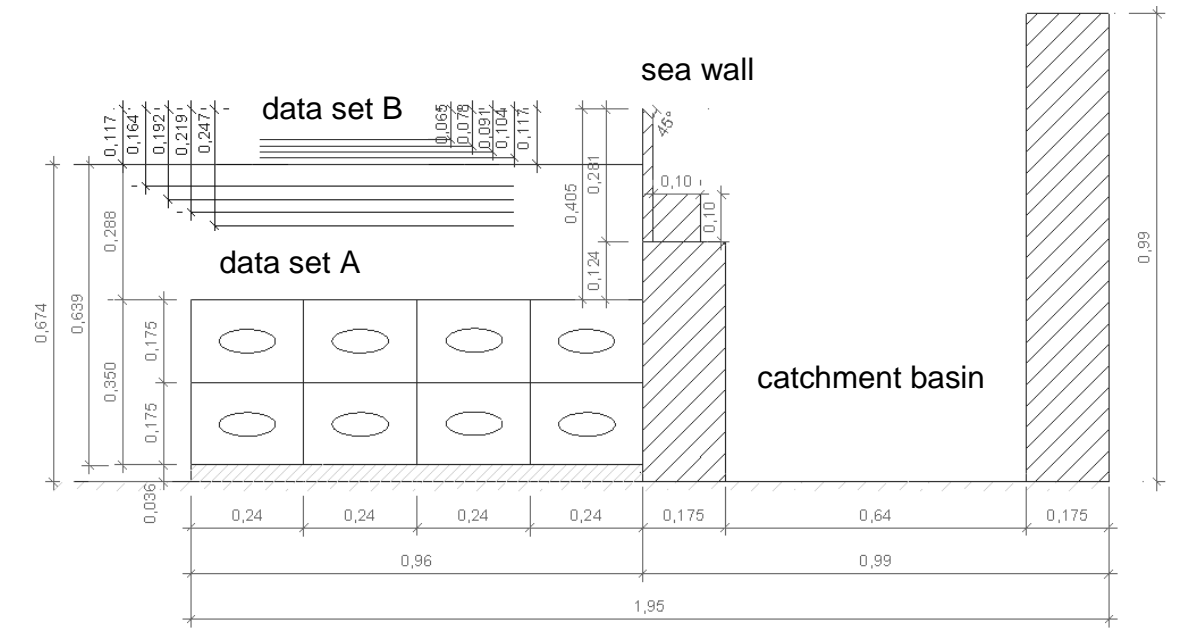

Figure 1. Geometry 1 representing a dyke with topped vertical wall and submerged horizontal toe geometry (model dimensions with scale 1:10)

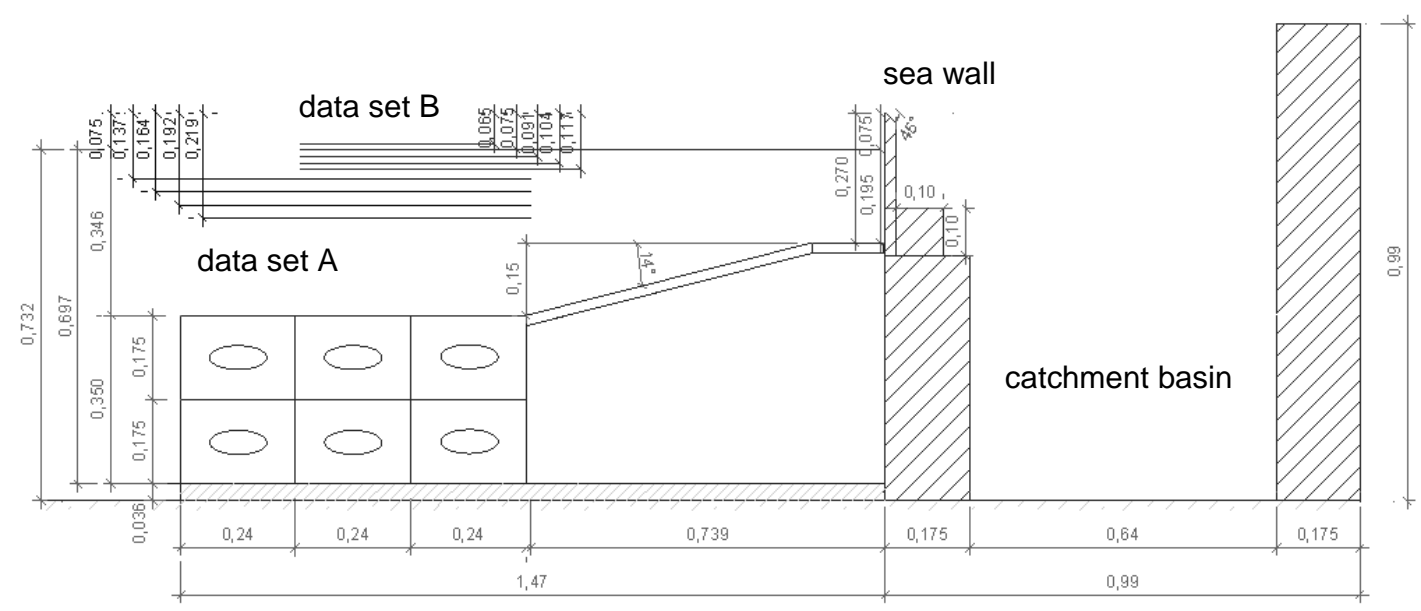

Figure 2. Geometry 2 representing a dyke with topped vertical wall and submerged horizontal toe geometry with additional 1:4 slope and submerged berm (model dimensions with scale 1:10) 
Two synthetic wave spectra are generated and analyzed in interaction with the two structures (data set A: $T_{m-1,0}=3.5 \mathrm{~s}, H_{m 0}=1.37 \mathrm{~m}$, peak wave steepness $s_{p}=0.059$; data set B: $T_{m-1,0}=2.3 \mathrm{~s}$, $\left.H_{m 0}=0.65 \mathrm{~m}, s_{p}=0.065\right)$ representing typical in-situ conditions with a duration of more than 1,000 waves per test. To improve the statistical validity and gain insight about the natural variability of overtopping, experimental runs with normal wave attack $\left(\beta=0^{\circ}\right)$ are reproduced six times, while runs with oblique wave attack $\left(\beta=10^{\circ}, 20^{\circ}, 40^{\circ}, 50^{\circ}\right.$ and $\left.60^{\circ}\right)$ are repeated three times. Ensemble means of overtopping discharges for the five individual wave tanks for corresponding runs are calculated in order to assure data quality. Measuring the overtopping volumes in five separated areas allows for an analysis of scattering in overtopping rates along the dyke crest not discussed in this publication.

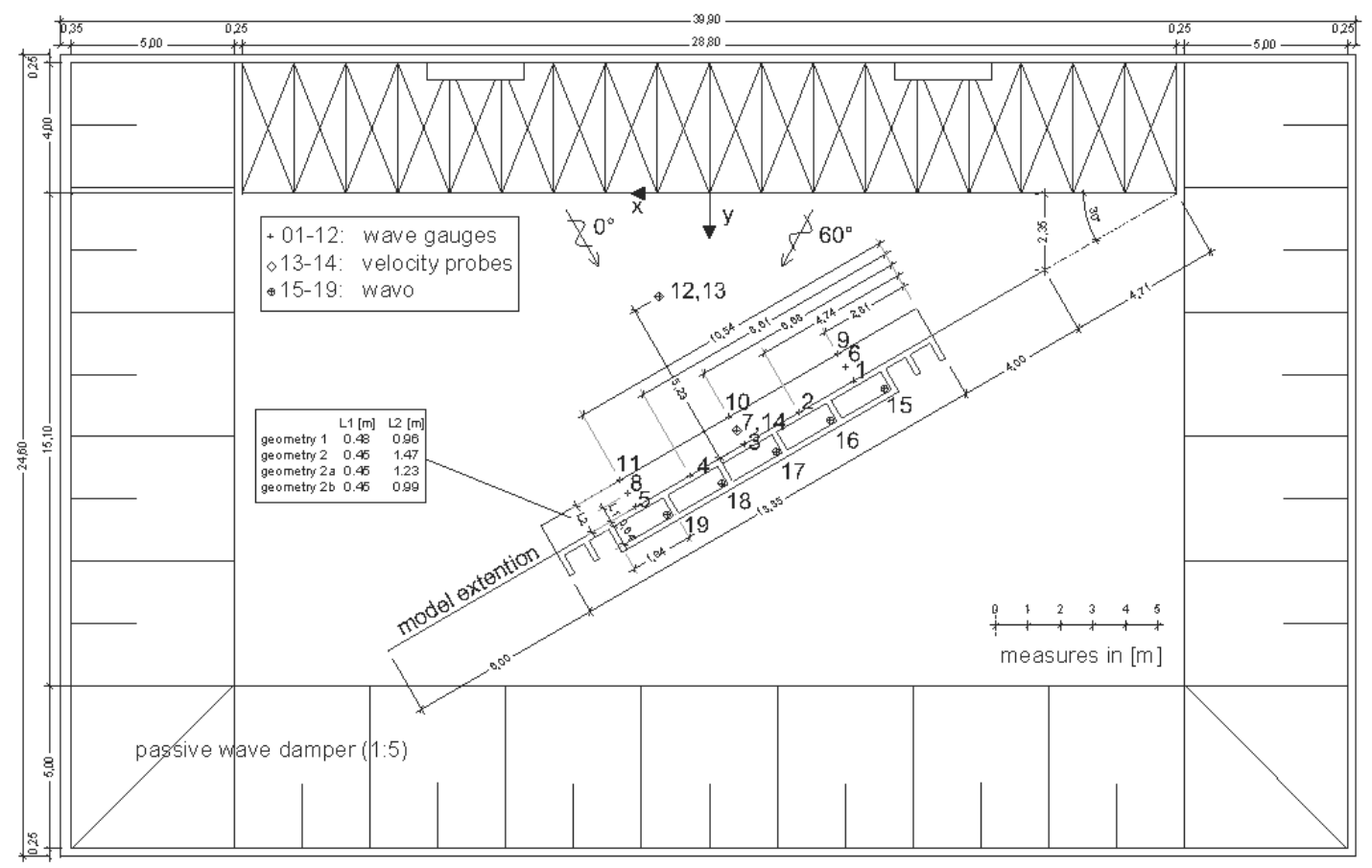

Figure 3. Plan View of 3D Basin and Model Layout.
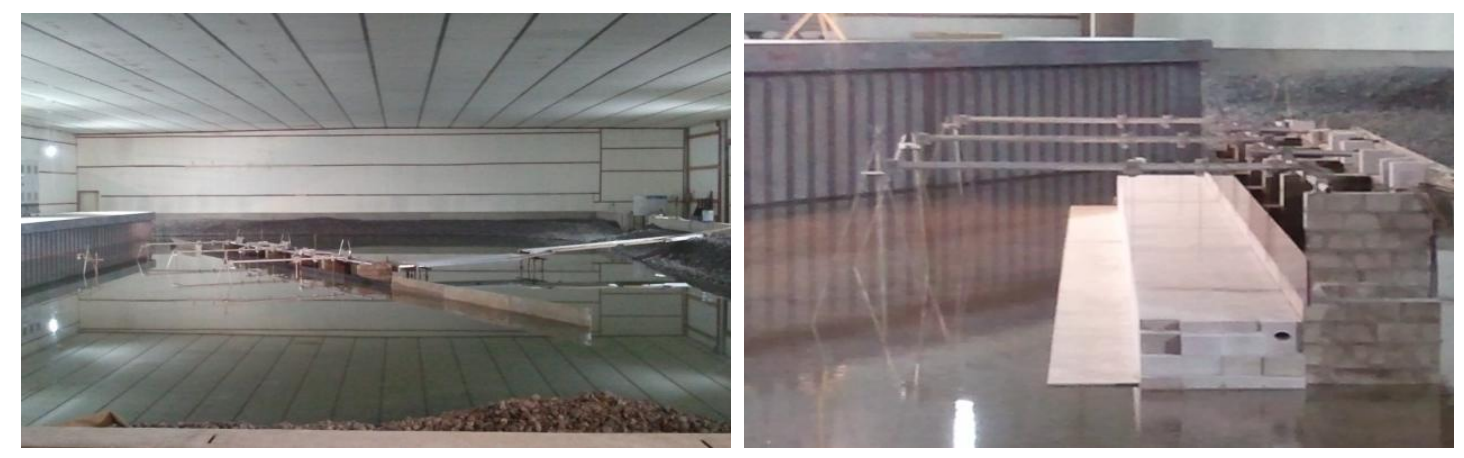

Figure 4. Set-up of Geometry 1 with instrumentation in the 3D wave basin.

\section{ANALYSIS OF MEAN OVERTOPPING DISCHARGE: CONCEPTUAL DESIGN FORMULAS}

The analytical prediction of the mean overtopping discharge $Q$ is usually resulting from empirical equations by means of interpolating results from hydraulic model investigations. In relevant literature Eq. (1) is usually used to calculate the dimensionless overtopping discharge.

$$
Q=a \cdot \exp (-b \cdot R)
$$

with the dimensionless overtopping discharge $\left.Q=q /\left(g H_{m 0}\right)^{3}\right)^{0.5}, R$ as the relative freeboard $R_{d} / H_{m 0}$ and coefficients $a$ and $b$ representing the best fitting regression for the results from hydraulic model 
tests. Given the results of several experimental investigations, TAW (2002) and EurOtop (2007) found the deterministic equation

$$
\frac{q}{\sqrt{g \cdot H_{m 0}^{3}}}=\frac{0.067}{\sqrt{\tan \alpha}} \cdot \gamma_{b} \cdot \xi_{m-1,0} \cdot \exp \left(-4.3 \frac{R_{c}}{\xi_{m-1,0} \cdot H_{m 0} \cdot \gamma_{b} \cdot \gamma_{f} \cdot \gamma_{\beta} \cdot \gamma_{v}}\right)
$$

where $q$ describes the overtopping volume per second and meter dike crest, $\alpha$ as the angle between overall structure slope and horizontal plane, $\xi_{m-1,0}$ as breaker parameter $\left(\xi_{m-1,0}<5\right), \gamma_{b}$ as correction factor for a berm, $\gamma_{f}$ as correction factor for permeability and roughness of or on the slope, $\gamma_{\beta}$ as correction factor for oblique wave attack and $\gamma_{v}$ as correction factor for a vertical wall on the slope. Eq. (2) can be used to calculate the dimensionless wave overtopping volume for non-breaking waves. The overtopping behaviour of waves at the two model geometries (Figure 1 and 2) is - at first hand anticipated to be similar to the performance of a vertical wall. Thus, the approach for non-impulsive conditions in front of vertical walls, given by

$$
\frac{q}{\sqrt{g \cdot H_{m 0}^{3}}}=0.04 \cdot \exp \left(-2.6 \frac{R_{c}}{H_{m 0} \cdot \gamma_{\beta}}\right)
$$

is compared with the results of the investigations presented in this study. According to EurOtop (2007) the influence of the wave direction on wave overtopping is defined by the influence factor

$$
\begin{array}{ll}
\gamma_{\beta}=\frac{q_{\beta>0}}{q_{\beta=0}}=1-0.0062|\beta| & \text { for }: 0^{\circ}<\beta<45^{\circ} \\
\gamma_{\beta}=0.72 & \text { for }: \beta \geq 45^{\circ}
\end{array}
$$

where $\beta$ depicts the angle of wave attack in relation to normal wave attack. A regression analysis of data sets provided by Franco (1999) for the preliminary prediction of the overtopping rate over a vertical wall breakwater in deep water under head-on, long-crested waves defines the mean wave overtopping volume $Q$ by

$$
Q=A \cdot \exp \left(-B \frac{R_{c}}{H_{m 0} \cdot \gamma_{\beta}}\right)
$$

with regression parameters $A=0.082$ and $B=3.0$ and an influence factor for oblique wave attack $\gamma_{\beta}$ defined by

$$
\begin{array}{ll}
\gamma_{\beta}=\cos \beta & \text { for }: 0^{\circ} \leq \beta \leq 37^{\circ} \\
\gamma_{\beta}=0.79 & \text { for }: \beta>37^{\circ}
\end{array}
$$

Goda (2009) formulates Eq. 7 from a total of 715 CLASH data sets and indicates an overestimation of large overtopping rates and underestimation of small overtopping rates of the formulas recommended in the EurOtop Manual to

$$
Q=\exp \left(-3.4-2.3 \frac{R_{c}}{H_{m 0} \cdot \gamma_{\beta}}\right)
$$

with an influence factor for oblique wave attack shown in Eq. (8).

$$
\gamma_{\beta}=1-0.0096|\beta|+0.000054 \beta^{2} \quad \text { for : } 0^{\circ} \leq \beta \leq 80^{\circ}
$$

According to Goda (2009) the factor represents data of large scatter and has to be investigated for validity with many sets of further test data.

\section{Hydraulic model test results}

The measured overtopping discharge $q$ under perpendicular wave attack is shown in Figure 5. The mean overtopping discharge $\left.Q=q /\left(\mathrm{gH}_{m 0}\right)^{3}\right)^{0.5}$ is plotted dimensionless in a semi-logarithmic scale over the dimensionless freeboard height $R_{d} / H_{m 0}$. Mean overtopping volumes $Q$ decrease with increasing 
freeboard height $R$ independent from dyke geometry and wave set-up. Due to the influence of the relative water depth $H_{m} d d$ directly in front of the vertical wall, incoming waves of data Set B are less intensively affected by the submerged toe both given geometry 1 and geometry 2 in comparison to waves of data set A. Hence, the dimensionless wave overtopping is higher for data set B. Generally, the mean wave overtopping rate increases for decreasing relative water depth directly in front of the vertical wall. All measured mean overtopping rates are well described by the deterministic approach given in EurOtop (2007) which expresses the upper boundary of the tested data sets. The approach by Franco (1999) fits very well to results of perpendicular wave attack of data set A at geometry 1.

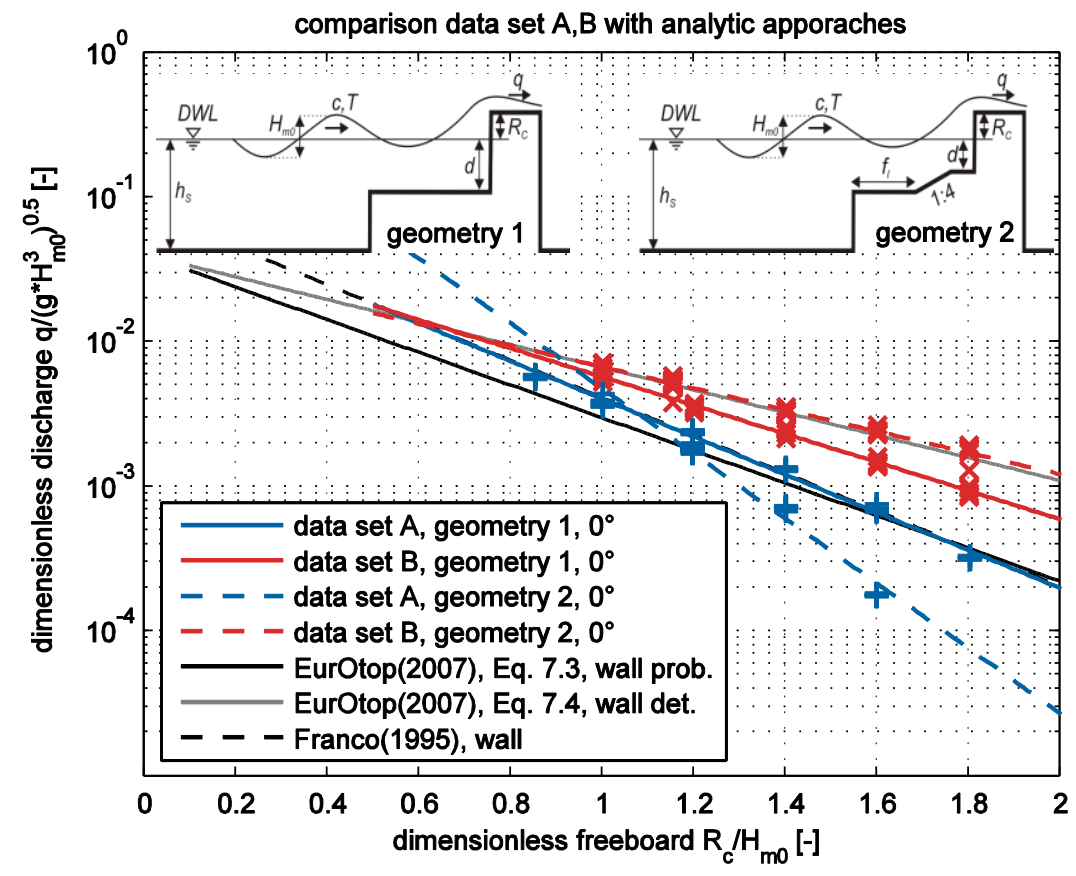

Figure 5. Comparison of measured mean overtopping rates for data set $A$ and $B$ under perpendicular wave attack $\left(\beta=0^{\circ}\right)$ with analytical approaches by EurOtop (2007) and Franco (1995).

By means of exponential regression of the measured data sets four regression parameters $a$ and $b$ given in Table 1 can be derived to describe the correlation between dimensionless mean wave overtopping discharge $Q$ and dimensionless freeboard $R$ according to Eq. (1).

\begin{tabular}{|c|c|c|c|c|}
\hline & \multicolumn{2}{|c|}{ data set $A$} & \multicolumn{2}{|c|}{ data set B } \\
\hline & $a$ & $b$ & $a$ & $b$ \\
\hline geometry 1 & 0.085 & 3.007 & 0.745 & 5.1 \\
\hline geometry 2 & 0.052 & 2.237 & 0.037 & 1.698 \\
\hline
\end{tabular}

Based on the four formulas resulting from Eq. (1) and with the regression parameters $a$ and $b$ given in Table 1 , the influence of oblique wave attack with angles $\beta\left\{10^{\circ}, 20^{\circ}, 30^{\circ}, 40^{\circ}, 50^{\circ}, 60^{\circ}\right\}$ on wave overtopping at the two tested geometries is further analyzed. Figure 6 shows the decrease of mean overtopping discharges in correlation with the dimensionless freeboard with increasing obliqueness $\beta$ for data set A and B at geometry 1 exemplarily. The same trend and performance can be observed for geometry 2 which is not shown in the following. It is obvious that the mean wave overtopping rate decreases with increasing dimensionless freeboard. This effect is originated by a reduction of the propagation energy component perpendicular to the dyke crest, and, a concurrent decrease in dimensionless discharge with an increase in obliqueness of the approaching waves which is in line with an enlarged propagation distance in shallow water conditions over the submerged toe. A less dominant decrease for data set B is observed due to a less pronounced interaction of the incoming waves with the submerged toe of the structure as depicted in Figure 6. 

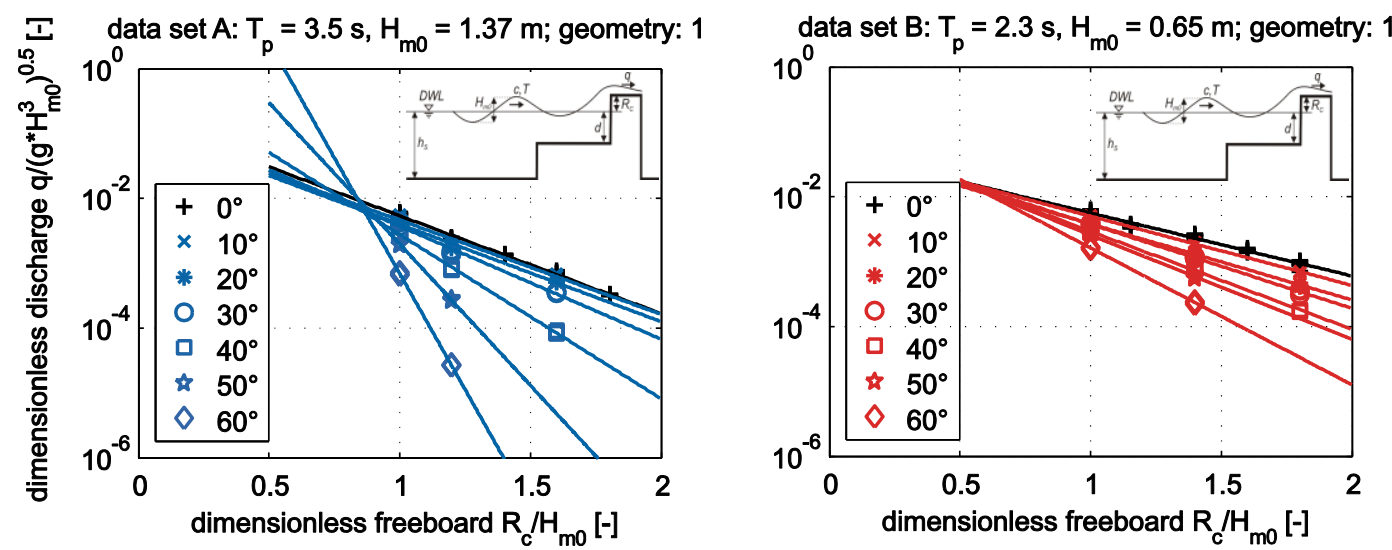

Figure 6. Influence of oblique wave attack on the mean wave overtopping discharge at geometry 1 (left: data set $A$, right: data set $B$ )

The influence factor $\gamma_{\beta}$ for obliqueness can be derived from Eq. (5) to

$$
\gamma_{\beta}=\frac{-B \cdot R_{c} / H_{m 0}}{\ln (Q / A)}[-]
$$

With regression factors $A$ and $B$ defined as $a$ and $b$ in Table 1 the influence factor $\gamma_{\beta}$ can be determined. The result is shown in Figure 7 as a function of the angle of wave attack $\beta$ for the analyzed test conditions. Furthermore, given analytical approaches defined in Eqs. (4), (6) and (8) are shown for better assessment of the present experimental results.

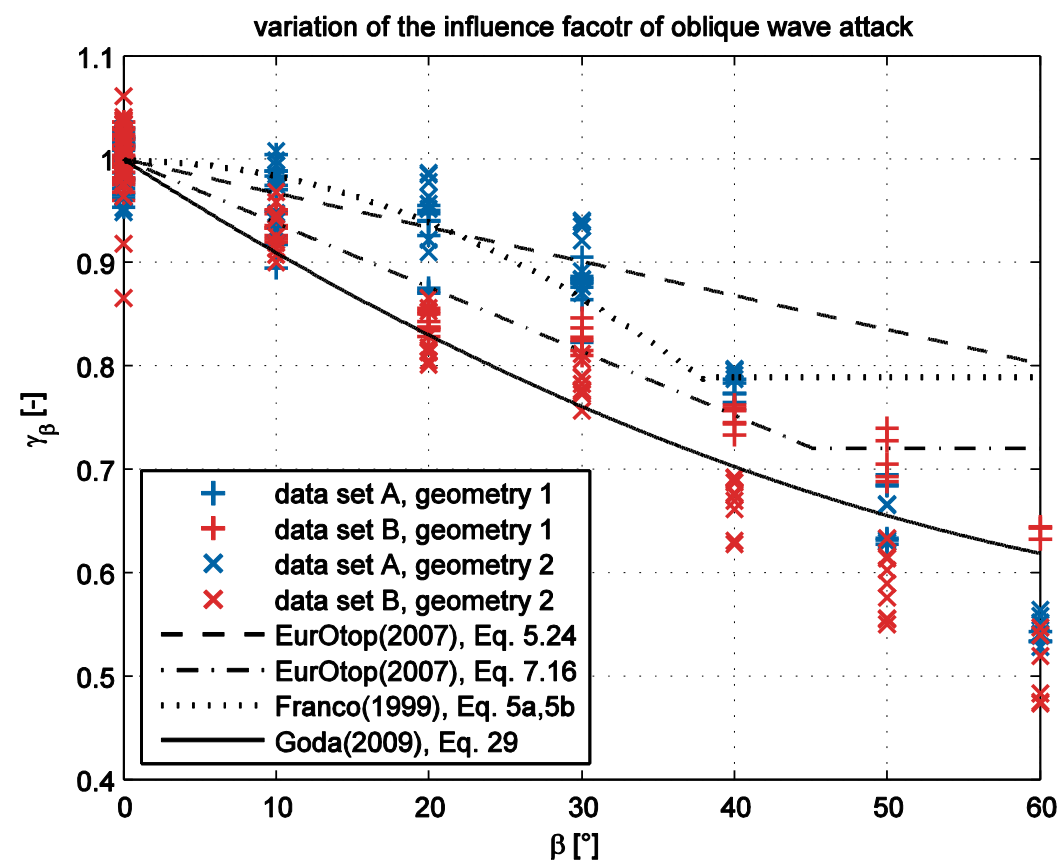

Figure 7. Comparison of the influence factor $\gamma_{\beta}$ for oblique wave attack between measurements and analytical approaches by Franco (1999), EurOtop (2007) and Goda (2009)

Compared with the approaches given in the EurOtop (2007) for complex composite structures, outcome for geometry 1 and 2 of data set A fit for small angles $\beta<30^{\circ}$, but are overestimated for increasing angles of wave attack. All results for data set B are overestimated with this approach. Eq. (4) (EurOtop, 2007) for vertical wall geometries fits best for the mean value of all test runs for $\beta<45^{\circ}$. For 
greater angles of wave attack all measured values are significantly overestimated by this formulation. The approach followed in Eq. (6) (Franco, 1999) expresses the measurements of data set A for $\beta<37^{\circ}$ and clearly overestimates data for larger wave attack angles. Instead, a disproportionately high decrease of $\gamma_{\beta}$ with increasing angle $\beta$ up to $37^{\circ}$ due to the cosine correlation is revealed. Eq. (8) (Goda, 2009) evidently outlines an underestimation of $\gamma_{\beta}$ for $10^{\circ}<\beta<30^{\circ}$ and a clear overestimation for $\beta>50^{\circ}$. This formulation shows a disproportionately low decrease of the influence factor $\gamma_{\beta}$ with increasing wave attack $\beta$.

With a quadratic regression attempt to fit the data shown in Figure 7 for the influence factor $\gamma_{\beta}$, regression parameter and matching results are followed according to

$$
\gamma_{\beta}=A 1+B 1|\beta|+C 1 \beta^{2}
$$

depicted regression parameters $A 1, B 1$ and $C 1$ which can be easily defined according to Table 2 .

\begin{tabular}{l}
\hline Table 2. Regression parameter $\boldsymbol{a}$ and $\boldsymbol{b}$ derived from hydraulic model tests \\
\hline
\end{tabular}

Obviously, the reduction factor $\gamma_{\beta}$ follows a nonlinear correlation for increasing angles of wave attack $\beta$ for data set $\mathrm{A}$ and $\mathrm{B}$. The influence of the dyke geometry is less dominant for data set $\mathrm{A}$ than for data set $\mathrm{B}$ where the factor $\gamma_{\beta}$ decreases significantly for $\beta>30^{\circ}$. For an increasing angle $\beta$ the influence factor $\gamma_{\beta}$ is decreasing disproportionately for data set $\mathrm{A}$ as previously outlined by Franco (1999) whereas it decreases unreasonably low for data set B as described by Goda (2009).

\section{CONCLUSIONS}

The results of a total of 336 three-dimensional model investigations on the overtopping performance of wave spectra at two composite dyke geometries with topped vertical walls and submerged toe geometries have been analyzed in order to evaluate the applicability of existing design formulas. Furthermore, the experiment data can be used for the assessment and validation of a numerical models as well as to improve existing design criteria.

The model test conditions depict two representative dyke geometries located in urban areas along German estuaries at the North Sea coast and are provided by the German Coastal Research Center (FSK, NLWKN). Two authentic wave spectra with spectral period of $T_{m-1,0}=2.3 \mathrm{~s}$ and $3.5 \mathrm{~s}$, significant wave height $H_{m 0}=0.65 \mathrm{~m}$ and $1.37 \mathrm{~m}$ and peak wave steepness of $s_{p}=0.065$ and $s_{p}=0.059$ have been analyzed. The validity of the proposed formulas is thus limited to these ranges, which however cover typical conditions occurring in the aforementioned region.

The study approves the decrease of wave overtopping rates with increasing freeboard heights for all conducted test runs. The level of the reduction is more dependent on the wave spectra than on the dyke geometry. The mean wave overtopping rate increases with decreasing relative water depth $H_{m o} / d$ directly in front of the vertical wall. On the other hand side, overtopping volumes decrease with increasing obliqueness of wave attack. The intensity is dependent on the wave-structure interaction and differs according to the incoming wave set-up. Moreover, a non-linear character of the obliqueness factor $\gamma_{\beta}$ describing the decrease of wave overtopping rates with increasing angle of wave attack $\beta$ has been determined. The correlation between mean wave overtopping rate and freeboard height has been defined in four newly adapted design formulations which clearly describe the overtopping performance at the two discussed dyke geometries. Furthermore, performance was assessed with approaches by Franco (1999), EurOtop (2007) and Goda (2009). Evidently, a trend to result in an agreement of the Franco (1999) approach with the results from data set A for geometry 1 with $\beta<37^{\circ}$ and an agreement of the Goda (2009) approach with data set B for geometries 1 and 2 was detected.

Further studies with an expanded range of wave spectra are currently conducted to formulate a generally accepted approach for the tested coastal protection structures and to figure out main drivers and inherent interactions for the evident non-linear reduction of $\gamma_{\beta}$.

\section{ACKNOWLEDGMENTS}

The hydraulic model tests are requested and assigned by the Lower Saxony Water Management, Coastal Defense and Nature Conservation Agency (NLWKN) - Coastal Research Center (FSK), An 
der Mühle 5, 26548 Norderney, GERMANY. The results of these hydraulic model tests will be used to validate the performance of a numerical model developed by $\mathrm{C}$. Berkenbrink.

\section{REFERENCES}

Daemrich K.-F. et al. 2006. Irregular Wave Overtopping Based on Regular Wave Tests, Third ChineseGerman Joint Symposium on Coastal and Ocean Engineering, Tainan.

Franco C. et al. 1999. Overtopping Formulas for Caisson Breakwaters with Nonbreaking 3D Waves, Journal of Waterway, ort, Coastal, and Ocean Engineering, pp. 98-107.

EurOtop: "European Overtopping Manual", KFKI, Eds Pullen, T., Allsop, N.W.H., Bruce, T., Kortenhaus, A, Schüttrumpf, H. \& van der Meer, J.W. 2007. Assessment Manual for Wave Overtopping of Sea Defences and Related Structures. www.overtopping-manual.com.

Goda, Y. 2009. Derivation of unified wave overtopping formulas for seawalls with smooth, impermeable surfaces based on selected CLASH datasets, Coastal Engineering 56, pp. 385-399.

IPCC 2007: Zusammenfassung für politische Entscheidungsträger. In: Klimaänderung 2007: Wissenschaftliche Grundlagen. Beitrag der Arbeitsgruppe I zum Vierten Sachstandsbericht des Zwischenstaatlichen Ausschusses für Klimaänderung (IPCC), Solomon, S., D. Qin, M. Manning, Z. Chen, M. Marquis, K.B. Averyt, M.Tignor und H.L. Miller, Eds., Cambridge University Press, Cambridge, United Kingdom und New York, NY, USA. Deutsche Übersetzung durch ProClim-, österreichisches Umweltbundesamt, deutsche IPCC-Koordinationsstelle, Bern/Wien/Berlin, 2007.

Napp, N., Pearson, J., Bruce, T., Allsop, W. 2003. Violent overtopping of vertical seawalls under oblique wave conditions, Coastal Structures 2003 - Proceedings of the Conference, pp. 528-541.

Tautenhain E. 1981. Der Wellenüberlauf an Seedeichen unter Berücksichtigung des Wellenauflaufs, Mitteilungen des Franzius-Instituts. H. 53 (1981), pp. 1-245.

Van der Meer J.W. and Janssen J.P.F.M. 1995. Wave run-up and wave overtopping at dikes, In: Z. Demirbilek, Editor, Published in: Wave Forces on Inclined and Vertical Structures, ASCE, pp. 127.

Wassing, F. 1957. Model investigations on wave run-up carried out in the Netherlands during the past twenty years, Proc. 6th Ing. Conference on Coastal Engineering, Gainesville, pp. 700-714. 